\title{
La pluralidad necesaria: Butler, Anzaldúa y el pensamiento postnietzscheano ${ }^{1}$
}

The necessary plurality: Butler, Anzaldúa and Nietzschean Studies

\author{
Sigifredo Esquivel Marín ${ }^{2}$ \\ Leobardo Villegas Mariscal ${ }^{3}$ \\ Universidad Autónoma de Zacatecas
}

Recibido: 15.10 .2021

Aceptado: 10.12 .2021

\section{Resumen}

El presente trabajo elucida el axioma de "la pluralidad necesaria" a partir de algunas calas y notas del pensamiento de Judith Butler y algunos cruces procedentes de la filosofía de Michel Foucault y Friedrich Nietzsche, así como el influjo postnietzscheano contemporáneo, en contraste con el pensamiento mestizo subalterno latinoamericano de Gloria Anzaldúa. La hipótesis central es explicada en estos términos: no existe ningún fundamento metafísico que sustente al mundo; todo es una construcción cultural, resultado del poder predominante en un determinado contexto histórico. El poder es el que establece lo que es normal o anormal, lo que está permitido o no está permitido. En este contexto, se postula la necesidad de someter a los dispositivos de poder reinantes, en las sociedades contemporáneas, bajo una revisión crítica que permita transformarlos en dispositivos de poder que hagan posible sociedades plurales e incluyentes. Y justo aquí, en la apertura de un nuevo horizonte postmetafísico y post-humanista es retomada la perspectiva mestiza subalterna de Gloria Anzaldúa como una

\footnotetext{
${ }^{1}$ El artículo es producto de la investigación colegiada y docencia en el Doctorado en Filosofía e Historia de las Ideas de la Universidad Autónoma de Zacatecas.

2 sigifredo.esquivel@uaz.edu.mx

https://orcid.org/0000-0001-8283-9659

3 leobardovillegas@yahoo.com.mx

https://orcid.org/0000-0003-4401-6760
} 
forma radical de repensar la condición humana más allá del euro-logo-falocentrismo desde los márgenes de América Latina. La pluralidad necesaria, lejos de ser un título contradictorio, es, antes bien, un título que expresa una afirmación, a saber, la necesidad de una realidad social plural, inclusiva, en la que las diferencias entre los seres humanos sean respetadas, siguiendo el ideal de una sociedad democrática en la que se cultive la apertura a los otros, en un ambiente de convivencia y diálogo.

Palabras clave: Sexo, Género, Pluralidad necesaria, Poder, Mestizaje Subalterno.

\begin{abstract}
The present work elucidates the axiom of "the necessary plurality" from some coves and notes of the thought of Judith Butler and some crosses coming from the philosophy of Michel Foucault and Friedrich Nietzsche, as well as the contemporary postnietzschean influence, in contrast to the thought Latin American subaltern mestizo of Gloria Anzaldúa. The central Nietzschean hypothesis is explained in these terms: there is no metaphysical foundation that sustains the world; everything is a cultural construction, the result of the prevailing power in a given historical context. Power is what establishes what is normal or abnormal, what is allowed or not allowed. In this context, the need to submit the reigning power devices in contemporary societies under a critical review that allows them to transform them into power devices that make plural and inclusive societies possible. And right here, in the opening of a new post-metaphysical and post-humanist horizon, the subaltern mestizo perspective of Gloria Anzaldúa is retaken as a radical way of rethinking the human condition beyond Euro-logophallocentrism from the margins of Latin America. The necessary plurality, far from being a contradictory title, is, rather, a title that expresses an affirmation, namely, the need for a plural, inclusive social reality, in which the differences between human beings are respected, following the ideal of a democratic society in which openness to others is cultivated, in an atmosphere of coexistence and dialogue.
\end{abstract}

Keywords: Sex, Gender, Necessary plurality, Power, Mestizaje Subaltern. 
"Si hay una tarea normativa positiva en El género en disputa, es insistir en la extensión de legitimidad a los cuerpos que han sido vistos como falsos, irreales e ininteligibles" (Butler, 2001, p. 21).

\section{El juego posmoderno: del aplanamiento del discurso a un pluralismo sociopolítico}

La tentación de los fundamentos definitivos ha cesado. La idea de una gran explicación capaz de revelar el secreto del universo no sólo ha resultado una metáfora gastada, sino que parece ser completamente inviable. La creencia de que el devenir histórico transcurre hacia un estadio mejor resulta, ahora, una desilusión. Respecto del conocimiento: ha sido invadido por la incertidumbre, lo mismo que el ser humano por la fantasía de su próxima desaparición. ${ }^{4}$ ¿Y los sexos? Ahora saben que son artificios culturales que pueden proliferar en la calidez (el aire fresco) del equívoco, ambigüedad, incoherencia e incertidumbre. En suma, es el tiempo de las identidades rotas y fisuradas, del fin de lo real. Para Baudrillard (1993) la creencia en la realidad aún constituye un remanente de las formas elementales de la vida religiosa. Considera que las creencias constituyen una debilidad del entendimiento y del sentido común, y "la última trinchera de los celadores de la moral y apóstoles de lo racional. Afortunadamente, nadie, ni siquiera los que lo profesan, vive de acuerdo con ese principio, y con razón. Nadie cree básicamente en lo real, ni en la evidencia de su vida real” (Baudrillard, 1993, p. 131). Las creencias más solidas se desvanecen, en realidad todo se erosiona y se fragmenta, empezando por la misma idea de totalidad; "el todo es la mentira" - ya había sugerido Theodor Adorno (2005) en su Dialéctica negativa-.

Asistimos a la emergencia de una serie de paradojas, singularidades del juego posmoderno: el crepúsculo de la verdad, el perspectivismo radical, las ruinas circulares del pensamiento, y también, la emergencia de nuevos desafíos culturales e intelectuales. Y aún más: "Hay muchos juegos del lenguaje diferentes, es la heterogeneidad de los elementos. Sólo dan lugar a una

\footnotetext{
${ }^{4}$ Nos referimos tanto a las fantasías cinematográficas donde las máquinas inteligentes se adueñan del universo, por ejemplo, Inteligencia artificial y Matrix, como a los pronósticos nada halagüeños de la crisis del cambio climático.
} 
institución por capas, es el determinismo local" (Lyotard, 1990, p. 10). De igual modo se anuncia la era de la proliferación de relatos y meta-relatos, se habla de forma sintomática de la posverdad, como si la verdad fuera un fetiche anquilosado, al tiempo, que el pensamiento hegemónico busca imponerse como sacrosanta verdad incuestionable.

Ya en uno de sus enigmáticos y bellos textos, Pierre Klossowski -siguiendo las intuiciones nietzscheanas- señalaba las inquietantes consecuencias de que el mundo devenga fábula. Al suprimirse el mundo verdadero también se suprime el mundo de las apariencias:

Junto con el mundo verdadero hemos suprimido el mundo aparente; cuando desaparece el mundo verdadero (platónico, cristiano, espiritualista, trascendente), que sirve de referencia al mundo aparente, desaparece a su vez la apariencia; el mundo se convierte en fábula, el mundo tal como es, no es más que fábula: fábula significa algo que se narra y sólo existe en el relato. El mundo es algo que se narra, un evento narrado y, por lo tanto, una interpretación. (Klossowski, 2008, pp. 186-187)

Religión, arte, ciencia, historia, filosofía... no son sino interpretaciones y variaciones de la fábula humana. El devenir fábula del mundo se co-implica, se complica, en el fin de los grandes relatos de la modernidad. Entre el devenir fábula del mundo y la muerte de Dios como consumación de una risa funesta ante el monoteísmo, Klossowski encuentra, de la mano de Nietzsche, una extraña complicidad. El mundo deviene fábula bajo el cumplimiento de la muerte de Dios como fin de toda garantía trascendente. Dios como garante absoluto de "la identidad del yo responsable desaparece en el horizonte de la conciencia de Nietzsche, quien a su vez se confunde con esta desaparición. Si la noción de identidad se volatiliza, no queda más que lo fortuito que adviene a la conciencia” (Klossowski, 2008, p. 211).

La posmodernidad radicaliza la muerte de Dios bajo la muerte del Hombre Universal como albacea testamentaria. Habitamos las ruinas de una modernidad capitalista que no cesa, en sus últimos estertores, de producir iatrogenias perversas y espantosas. Nos precipitamos en un estado de crisis radical donde todas las significaciones imaginarias centrales de la modernidad 
ilustrada se deslegitiman o pierden significación relevante, sin alcanzar a ver la apertura de otro horizonte por venir. Estamos en un estado de impasse, una zona fronteriza entre un pasado ruinoso y un futuro que no acaba de nacer del todo. Radicalizando el perspectivismo nietzscheano, Klossowski y Baudrillard nos han mostrado el callejón sin salida del ideario político e intelectual de la modernidad logocéntrica, empero se han confinado a entonar el melancólico réquiem del adiós a la razón moderna universalista sin posibilitar alternativas de transvaloración. Aclaremos: autores como Klossowski y Foucault no se inscriben en el posmodernismo de forma explícita, pero, sin lugar a duda, creemos que capturan la esencia de dicho pensamiento de manera muchos más fehaciente que muchos adalides posmodernistas. En efecto, el pensamiento postnietzscheano de estos dos pensadores excepcionales expresa el dilema central de pensar(se) a partir de "la muerte de Dios" y la búsqueda de nuevos fundamentos que sean capaces de trastocar el relativismo imperante sin caer nuevos absolutismos metafísicos, nos permiten transitar del aplanamiento del discurso, epifenómeno del fin de los grandes relatos en la posmodernidad, hacia un pluralismo sociopolítico capaz de dotar de sentido un pensamiento finito desde la mortalidad extrema que no renuncia a repensar la diversidad que encarna la multiplicidad de la vida misma.

\section{Las máscaras del poder}

Uno de los temas esenciales en el pensamiento de Michel Foucault es el poder y su relación con la configuración y re-configuración del sujeto y su entorno. La forma en que el poder es tratado en el contexto del pensamiento de este autor es novedosa en el sentido de que no se le asume como algo que posea y ejerza una persona o grupo social determinado. No. El poder debe ser entendido en una perspectiva relacional, microfísica, polivalente, compleja, mucho más amplia y dinámica, es decir, se encuentra en todos los rincones del mundo humano; del mundo del espíritu -en términos de Hegel-.

Para Foucault, la vida se expresa en múltiples estrategias de poder y de resistencia, genera una urdimbre compleja, ambigua y contradictoria. El poder no sólo reprime o niega, también produce discursos, placeres, miedos, saberes, etc. Puede afirmarse que tiene, en gran medida, 
una esencia creadora. Recordemos el axioma foucaultiano: ahi donde hay poder, emerge la resistencia. Poder y resistencia se co-implican, se complican.

¿Somos víctimas o agentes del poder? Las dos cosas. En ocasiones el poder nos limita o nos manipula, en otras lo ejercemos para afirmar nuestros intereses. Y es que, socialmente hablando, es como el Tao de Lao-Tse: no hay un sitio donde no se advierta, donde no se le sorprenda o nos sorprenda. El poder se difumina, carece de localización precisa, tampoco es exclusividad "del Estado y de otras instituciones tradicionalmente «represoras»: el poder es multicéntrico y se disemina en mil manifestaciones, que incluyen las circunstancias más ordinarias de la vida” (Izuszquiza, 2002, p. 156). Estructura arborescente y dinámica, el poder se aproxima a una suerte de perfume o esencia que lo impregna y contamina todo.

Según esta óptica, la posición metafísica que sostiene que hay realidades establecidas eternamente es absurda. Todo (la verdad, la moral, el sexo...) es resultado de los distintos discursos creados desde cierta posicionalidad en y desde el poder. Ahora bien, vivimos en tiempos de paradojas y contradicciones insolubles. Todo parece fragmentarse y diluirse, mientras que las formas de control y dominación se hacen cada vez más firmes e imperceptibles; lejos de desaparecer, se fortalecen. Y, sin embargo, ha operado una profunda mutación que apenas es posible dar cuenta de ella.

Quizá sea pertinente realizar hoy una relectura de la Posdata sobre las Sociedades de Control, de Deleuze, Gilles (2006) donde el autor replantea y radicaliza las conclusiones foucaultianas sobre las sociedades disciplinarias y el advenimiento de una nueva época. En esa relectura, la lógica que caracteriza a las sociedades disciplinarias se explica mediante la organización normativa y rigurosa de los grandes espacios de encierro (fábrica, escuela, prisión), mientras que, en las sociedades emergentes, que denomina, siguiendo a Burroughs, sociedades de control, no se administran nuevas formas de vigilancia sino de libertad. En ellas cada uno es libre de desplegar sus propios mecanismos de autocontrol; el modelo de empresa reemplaza al de la fábrica; cada uno se convierte en empresario de sí mismo. Formación y evaluación permanentes están tanto en el espacio laboral como en el espacio educativo. En las sociedades 
de control -considera Deleuze (2006) - lo esencial no ni una firma ni un número, sino una cifra, una contraseña; hoy se podría decir: un algoritmo. Estamos presenciando la emergencia de subjetivaciones y formas de control algorítmicas. Los juegos de subjetivación del control resultan más bien ondulatorios, operan por modulación, mediante variaciones complejas.

Bajo el advenimiento de las sociedades del hiper-control, el capitalismo se despliega como hiper-consumo generalizado, lo cual no excluye la creciente pobreza de más de la mitad de la población mundial. Las formas de poder tienden a difuminarse de forma rizomática, arborescente, infinitesimal e imperceptible, pero ahora es cuando los grilletes son quizá más férreos porque es un trabajo personalizado y a la carta que la propia lógica de individuación posmodernista ha radicalizado bajo el canto de las sirenas virtuales de una libertad hedonista afectiva subjetiva. La subjetivación posmoderna está lejos de ofrecernos mayor libertad efectiva, todo lo contrario, está llevando a extremos insospechados nuevas formas de dominación como autocontrol del mismo sujeto. La lógica de las sociedades de control tiende a radicalizar las formas y estrategias de dominación, hace cada vez más difícil la lucha por la libertad, la autonomía y la emancipación. El Estado posmoderno, lejos de volverse minimalista como cierta lectura neoliberal clama, se vuelve más autoritario y (proto)fascista, radicaliza y extrema formas de destrucción de la vida humana y natural. Los espacios de autonomía y lucha cada vez están más acotados, delimitados, reducidos. Hoy se impone una lógica global de devastación, nunca antes conocida, apenas entrevista por las utopías negativas más apocalípticas, la ciencia ficción más pesimista y catastrófica ha quedado superada por una realidad que se vuele irreal.

El desafío de nuestro tiempo es repensar la producción de subjetividad en los umbrales del sistema-mundo-capitalista en y desde otra perspectiva que sea más dinámica, dúctil, plástica, creativa y pueda dar cuenta de la diversidad humana a partir de la creación de nuevos valores y marcos normativos capaces de reorientan formas otras de vivencias y convivencias donde el disenso y la alteridad auténticos sean parte medular de nuestra vida cotidiana. En este sentido, Foucault, el posmodernismo y el postestructuralismo han dado algunos pasos significativos para visibilizar uno de los temas y problemas fundamentales de nuestro tiempo,

Volumen 2. Número 1. Enero - Junio 2022 
a saber, la real inclusión del otro y de los otros sin menoscabo de su dignidad ontológica y participación sociopolítica activa en una sociedad que afirme la diversidad como eje central de su dinámica cotidiana.

\section{Cartografía de subjetividades, cultura y género (notas a partir de Judith Butler)}

La pasión por lo absoluto, lo que permanece, lo que no cambia, lo universalmente verdadero, recorre la historia de la filosofía. Heredera de Foucault y Nietzsche, el pensamiento de Judith Butler se sitúa más acá de esa pasión. Escritora inteligente, aguda filósofa, sus propuestas teóricas son indudablemente polémicas e interesantes. Antes de analizarlas, dejemos que nos hable un poco de sí misma: "La única forma de describirme durante mis años de juventud en Estados Unidos es como una lesbiana de bar que se pasaba el día leyendo a Hegel y la noche en un bar gay que ocasionalmente se convertía en un bar drag” (Butler, 2006, p. 301). Empero, lejos de las frivolidades intelectuales reinantes, el pensamiento de Butler se sitúa en el corazón del presente de manera siempre crítica, la autora ha hecho de la renovación del pensamiento crítico uno de sus estandartes más preclaros e insignes, si bien, como ella misma nos aclara, no hay crítica sino es siempre desde un espacio discursivo y de interacción situado en contexto muy específico: "La crítica es siempre crítica de alguna práctica, discurso, episteme o institución instituidos, y pierde su carácter en el momento en que se abstrae de esta forma de operar y se la aísla como una práctica pura- mente generalizable” (Butler, 2008, p. 141).

El problema central en el pensamiento de Butler es la cultura, sus formas y dispositivos de dominación, es decir, un mundo donde el concepto de Hombre $^{5}$ se ha inventado para asumir la sobrevivencia del falocentrismo. Siguiendo a Foucault y a la teoría crítica, para Butler se trataría de elucidar, mediante el pensamiento crítico, la trama del poder, la constelación de fuerzas y sus formas diversas de subjetivación. Al respecto, su posición se traduce en la idea

\footnotetext{
${ }^{5}$ Aquí utilizamos la categoría "Hombre" sin dejar de reconocer su adscripción al horizonte de un lenguaje heteronormativo obsoleto, aunque aún presente en el campo intelectual y cultural, terreno marcadamente falocentrista, eurocéntrico e imperialista. En ese lenguaje la categoría "Hombre" incluye y florcluye, a la vez, a la categoría de "mujer" como ente subalterno: correlato complementario del sujeto masculino (Cfr. Butler, 2005, pp. 179-203).
} 
de que ésta es una construcción configurada de una determinada manera, la cual perfectamente podría ser distinta. Ello es deseable, debido a que el modelo predominante es claramente injusto desde sus propios fundamentos. No sólo se trata de una injusticia cognitiva sino también ontológica, pues simplifica una realidad humana ya de suyo hiper-compleja. Dicho de otro modo: en el ámbito cultural, tal y como ha devenido hasta el presente, lo privilegiado es lo masculino sobre lo femenino. Lo impuesto arbitrariamente es el arquetipo de una cultura paternalista. Lo eurocéntrico frente a las otras culturas y tradiciones que son reducidas a fetiches exóticos de una antropología (física y metafísica) dogmática y totalitaria. Ello se advierte en el lenguaje de los saberes, en los procesos históricos, en la vida cotidiana de cualquier época... Hemos crecido dentro de una visión universalista hueca que nos ha despojado de toda posibilidad de tener otro entendimiento de uno mismo y del entorno.

En el fondo, todo es una cuestión de poder, en términos de Foucault. Poder que habría que desmenuzar desde el juego sociopolítico de producción de subjetividades genéricas. Esa es la explicación que Butler encuentra para la comprensión de dicha arbitrariedad. El poder, hay que aclararlo, es el que establece lo permitido, bueno, válido, verdadero y normal. Pero tampoco se trataría de adscribirse a una posición maniqueísta, donde pensamiento y cultura de Occidente y lo otro, o los otros, son la salvación de dicha crisis. Más bien se trata de asumir la herencia compleja occidental a partir de su ejercicio cruento de cuestionamiento, deconstrucción e impugnación. Para Butler (2008, p. 146), "la crítica es una práctica que requiere una cierta cantidad de paciencia, al igual que la lectura, de acuerdo con Nietzsche, requiere que actuemos un poco más como vacas que como humanos, aprendiendo el arte del lento rumiar". Por tanto, Butler enfatiza la exigencia de repensar el pensamiento crítico en y desde la misma configuración de los procesos y prácticas que configuran el campo sociocultural como un espacio eminentemente sociopolítico.

Afortunadamente, el campo sociocultural no es algo fijo, es cambiante, modificable, siempre está en constante formación, conformación y transformación; el inter-juego sociocultural está atravesado de antagonismos políticos pluralistas que nunca se dejan encerrar o atrapar en una identidad cultural fija o definitiva. Partiendo de esa evidencia, es posible concluir que todo es

Volumen 2. Número 1. Enero - Junio 2022 
contingente, más no necesariamente relativo. En tal lógica, las categorías culturales prevalecientes pueden y deben ser sometidas a una intensa revisión crítica. Según Butler: "No tengo claro que la realidad sea algo establecido de una vez por todas, y haríamos bien en instar a la especulación sobre la relación dinámica entre fantasía y la realización de nuevas realidades sociales" (Butler, 1990, p. 209).

La clave es no asumir nada en términos absolutos, lo cual implica una posición abiertamente postmoderna, empero, en el caso de Butler habría que matizar dicha afirmación porque ella suscribe el ideario foucaultiano y de la Teoría Crítica de Adorno en su búsqueda de replantear el legado de la conciencia crítica ilustrada en aras de defender un modelo de argumentación crítica que se entrene en "la capacidad de formar razones ligadas de forma importante a la relación transformadora" del sujeto respecto al entorno (Butler, 2008, p. 152). En tanto Butler considera irrenunciable el ideario libertario crítico del pensamiento moderno ilustrado se adscribe a la herencia de la modernidad, empero, impugna las narrativas modernas en tanto presuponen un sujeto universal racional falocéntrico. El falocentrismo impregna el imaginario social que asume una construcción genérica heterosexual normativa. Ahora bien, lo prevaleciente es la heterosexualidad (la sexualidad binaria), la idea de que sólo hay dos sexos, opuestos pero complementarios. En otras palabras: la convicción de que únicamente deben existir las categorías "hombre" y "mujer" no es otra cosa que un sello impuesto por unos intereses específicos. En consecuencia, es una mentira que se pretende irrefutable y que, por supuesto, hay que desenmascarar. Para lograrlo se precisa no perder de vista que nada hay por naturaleza, que la noción misma de un sexo natural es errónea. ¿Por qué pensar, entonces, que lo único concebible es la relación bipolar hombre-mujer? Hay que alejarse de esa superstición. En otras palabras ${ }^{6}$ :

\footnotetext{
${ }^{6}$ La autora que quizá ha tenido mayor influencia en el pensamiento de Judith Butler es la novelista, poeta y filósofa francesa Monique Wittig. De sus obras hay que destacar: Las guerrilleras y El cuerpo lesbiano. Entre sus formulaciones filosóficas cabe resaltar su idea de que el sexo es una marca impuesta por la cultura: "El sexo [...] es tomado como un 'rasgo físico', un 'dato inmediato', un dato sensible, perteneciente al orden natural. Pero lo que creemos que es una percepción física y directa sólo es una construcción sofisticada y mítica, una formación imaginaria, que reinterpreta los rasgos físicos (en sí mismos tan neutros como los demás, pero marcados por un sistema social) mediante la red de relaciones en la que son percibidos." Vid., Variaciones sobre sexo y género: Beauvoir, Wittig y Foucaul (Butler 1990, p. 202).
} 
Butler sigue a Wittig en su apuesta por la disolución de las limitaciones del esquema binario de dos géneros, pero su línea de acción invierte la opción de Wittig. La estrategia que Butler sigue es la de subvertir la identidad a partir de una proliferación de géneros, discontinuos e incoherentes, que lograría desbordar las ficciones culturales de coherencia heterosexual. En consecuencia, hay que actuar en la dirección diseñada por Foucault de multiplicar las diferencias en sus configuraciones con el fin de que las oposiciones binarias, siempre al servicio de la jerarquía, dejen de ser hegemónicas y se desarrollen relaciones de poder alternativas. (Burgos, 2002, p. 387)

A la cartografía intelectual le tendría que seguir la promoción de nuevas formas y estilos de subjetividad e intersubjetividad, así como la problematización de las formas socialmente instituidas que han configurado los patrones de dominación heteronormativos. En este sentido la tarea ingente de replantear el ejercicio de crítica y deconstrucción del falocentrismo es una tarea que conlleva la emergencia de nuevas e inéditas formas y estrategias de repensar las identidades genéricas.

El pensamiento crítico constituye una práctica discusiva y política que se encarna en una toma de posición muy concreta respecto a la construcción de relaciones de dominación. En este sentido Butler nos recuerda que para Foucault: "la crítica será el arte de la inservidumbre voluntaria, de la indocilidad reflexiva. La crítica tendría esencialmente una función de desujeción en el juego de la política de la verdad. La política de la verdad se refiere a las relaciones de poder que nos circunscriben" (Butler, p. 157). La resistencia, como efecto práctico del pensamiento crítico, hace frente, resiste ante las fuerzas de coerción mediante de la estilización de sí bajo límites establecidos que se muestran dúctiles y flexibles en vez de establecerse como estructuras rígidas. Opera toda una compleja interacción de relaciones muy oblicuas e intrincadas de poder y de saber que nos posibilitan pensar y actuar en el mundo. La crítica tendría que desplegarse como una praxis muy puntual de autocreación de sentido en los márgenes que posibilite a desujeción e insurrección de límites y leyes siempre flexibles.

Volumen 2. Número 1. Enero - Junio 2022 


\section{Judith Butler o el sexo mentiroso}

Todo lo que escapa a la dialéctica de la heterosexualidad ha sido visto con sospecha, como si se tratara de algo extraviado, perdido en cierta confusión indeseable. Y es que se sigue creyendo que las cosas deben ser de determinada manera, como si existiese una verdad arquetípica cuya función es dictaminar lo que es normal y lo que no lo es. Al respecto, las palabras de Foucault son esclarecedoras:

Sin embargo, la idea de que, al fin y al cabo, se debe tener un sexo verdadero está lejos de haber desaparecido por completo. Sea cual sea la opinión de los biólogos sobre este punto, se mantiene, aunque sea difusamente, la creencia de que entre el sexo y la verdad existen relaciones complejas, oscuras y esenciales -no sólo en la psiquiatría, el psicoanálisis o la psicología, sino también entre la gente de la calle. Se es, ciertamente, más tolerante con aquellas prácticas que transgreden las leyes. Pero se continúa pensando que algunas de ellas insultan a la "verdad": un hombre “pasivo”, una mujer "viril”, gente del mismo sexo que se ama entre sí... Puede que se esté dispuesto a admitir que todo esto no constituye un grave atentado contra el orden establecido, pero también se suele considerar con facilidad que existe en ellas algo así como un “error” entendido en un sentido filosófico más tradicional: una manera de proceder inadecuada a la realidad: la irregularidad sexual pertenecería, más o menos, al mundo de las quimeras. (Foucault, 1985, p. 14)

Lo que preocupa a Butler es la valoración positiva de las identidades sexuales calificadas como confusas o mentirosas según el dispositivo de poder reinante. ${ }^{7}$ Se trata de minar la idea conforme a la cual existe algo así como una verdad en el sexo. Ello se logra argumentando, como ya se expresó anteriormente, que la trama cultural no es una esencia metafísica, algo

\footnotetext{
${ }^{7}$ Al respecto, el análisis de la sexualidad de Foucault corrobora que lo que Butler postula en realidad ya existe; todo es cuestión de valorarlo en un horizonte más abierto e incluyente: "El siglo XIX y el nuestro fueron más bien la edad de la multiplicación: una dispersión de las sexualidades, un refuerzo de sus formas disparatadas, una implantación múltiple de las 'perversiones'. Nuestra época ha sido iniciadora de heterogeneidades sexuales" (Foucault, 1999, p. 49).
} 
que nos trascienda: son las relaciones que inventamos, que nosotros mismos creamos. Por tanto, aunque no todo es una convención, pues se trata de una multiplicidad de procesos y prácticas culturales sociopolíticas, lo cierto es que nada hay verdadero en un sentido absoluto. La cuestión importante es, entonces, intentar combinaciones distintas, más inclusivas y justas. Es decir, es posible cambiar las reglas, pero desde dentro de las mismas reglas; no existe un afuera: "El travestismo es un ejemplo que tiene por objeto establecer que la realidad no es tan fija como solemos suponer" (Butler, 2001, p. 21). En efecto, a partir de una resignificación de las categorías culturales puede sabotearse el modelo heterosexual y abrir el espectro de la normalidad sexual a otros géneros, como el homosexual, el travestido, el drag queen, el transexual y otras identidades sexuales genéricas emergentes, asumiendo que la identidad subjetivante, como Butler después lo va a reconocer, no es cuestión de un vestido que los sujetos se quitan y se ponen sin más, sino que el juego performativo conlleva también una dramaturgia existencial.

Debe tenerse en cuenta que, según Butler (2001), no hay un sujeto metafísico, un yo absoluto, una realidad previa. El yo depende de los otros: no es autónomo; siempre es en relación con una alteridad psíquica, pero también política y socioeconómica. El sujeto está construido desde fuera, con una identidad incoherente, lo que implica que todo es inestable, todo es performativo. Cierto, el yo aún existe como algún viejo prejuicio que sabemos a ciencia cierta que es falaz, pero le tenemos cierto aprecio; en lugar de un sujeto supuestamente sustancial o autodeterminante, nos queda solamente, como dirá Butler, una suerte de demandas discursivas que constituyen una especie de encrucijada de fuerzas políticas y culturales que ya no se pueden entender bajo la categoría metafísica de sujeto. Desde la genealogía del falocentrismo se puede desmontar críticamente que no hay ningún sujeto preexistente, que siempre emerge su constitución a partir de un trabajo arduo de construcciones y puestas en escena. El espacio de conformación de las subjetivaciones se despliega como una compleja trama relacional: "El espacio de esta ambivalencia es la que da la posibilidad de reelaborar los términos mismos mediante los cuales se da o no se da la sujeción" (Butler, 2005, p. 183). De tal suerte, que la re-elaboración de las subjetividades contemporáneas parte del juego que se despliega en dichos espacios y pliegues intersticiales. 
Tomando distancia de su célebre y ampliamente comentada obra El género en disputa, Butler (2005) matiza sus ideas y se da cuenta de que el travestismo y lo queer pueden contribuir a una "reidealización de las normas heterosexuales hiperbólicas de género" (p. 184). Se puede mantener el orden heteronormativo bajo los más diversos ropajes de apertura; algo similar sucede con el multiculturalismo posmoderno que deja intacto el orden monocultural hegemónico. En este sentido, su pensamiento, siempre atento al diálogo crítico, ha ido evolucionando en un sentido más bien táctico y estratégico de repensar el género siempre desde un contexto situado y en atención a una diversidad de textos y para-textos heterogéneos que puedan estar modificando la perspectiva analítica. Resulta difícil reconocer que no hay un actor $\mathrm{u}$ autor previo a lo actuado, toda actuación es performativa y constituye al sujeto como efecto y no como substancia fija:

Esta dificultad es producto de una predisposición a pensar la sexualidad y el género como ‘expresiones' directas o indirectas de una realidad psíquica que los precede. La negación de la prioridad del sujeto, sin embargo, no implica la negación del sujeto; de hecho, la negativa a reunir el sujeto con la psiquis indica que lo psíquico es algo que excede el dominio del sujeto consciente. Este exceso psíquico es sistemáticamente negado por la noción de un 'sujeto' volitiva quien elegiría a voluntad cuál género y/o sexualidad ser en cualquier momento y lugar. (Butler, 2000, p. 103)

El resultado: únicamente hay copias de copias; no existe un sexo original ni originario. Lo sexual es continente y continuo atravesado por multiplicidades e inter-sexualidades evanescentes y displicentes; ya ni siquiera del cambio se tiene certeza alguna. En la disolución del todo, emerge un juego de subjetivaciones anómalas, anormales, monstruosas, aberrantes, singulares, rizomáticas, mutantes, siempre al borde y en el desborde. Tal conceptualización se acerca a las nociones propuestas por Gilles Deleuze del cuerpo-sin-órganos y del devenir orquídea, aunque la propia Butler toma con precaución una posible alianza entre ecofeminismo y filosofía de la inmanencia, no deja de valorar la importancia de la obra deleuziana, misma que ha cuestionado radicalmente la idea de identidad fija. Básicamente, la 
idea de cuerpo-sin órganos problematiza la idea de organismo corporal como complemento de lo sujeto mental, comprendido como un todo jerarquizado y estructurado; por su parte, la idea del devenir orquídea da cuenta de las mutaciones que operan en el seno del juego sexual y ontológico de subjetivaciones minoritarias, disidentes y siempre transgresoras: "animalidad, infancia y feminidad valen por sus coeficientes de alteridad y alteración o de desterritorialización absoluta" (Zourabichvili, 2004, p. 30; cursivas del original y traducción nuestra).

No obstante, Butler asume sin ninguna coartada o excusa metafísica o retórica, la radical contingencia del mundo contemporáneo, la imposibilidad de encontrar fundamentos o argumentos trascendentales universales, de ahí su crítica y toma de distancia respecto a la pragmática universal de Habermas (Butler, 2008, p. 144), también asume la pensadora un compromiso enérgico que haga del pensamiento crítico una brújula para orientarnos en el caos actual, así como en la búsqueda de criterios y valores capaces de resignificar la dimensión ético-política de la existencia humana singular y colectiva. Frente a los modos de subjetivación heteronormativos, siguiendo a Nietzsche y a Foucault, Butler propone radicalizar un juego procesual finito-infinito de subjetivaciones plásticas, artísticas, creativas e insurrectas. En suma, se trataría de repensar modos y modelos de vida "en favor de una práctica más arriesgada que busca actuar con artisticidad ante la coacción” (Butler, 2008, p. 167). Esto conlleva hacer del pluralismo ontológico una apuesta y propuesta ético-política de afirmación de una pluralidad sustantiva en las distintas formas y acciones de subjetivaciones e intersubjetivaciones capaces de hacer de la diferencia y del disenso formas fundamentales de nuestra convivencia diaria. La pluralidad necesaria reafirma la búsqueda de valores y axiomas comunes bajo la contingencia más radical imperante.

\section{Apertura}

Las normas culturales son todo: nos forman y nos reprimen. Hay que transformarlas adjudicándoles nuevas significaciones desde su propio horizonte. Ahora bien, no todas las 
resignificaciones son deseables; unas si y otras no. No todo vale: vale el buen vivir, la comprensión. No la exclusión ni la calumnia:

Debemos asumir que nuestras convenciones ya establecidas acerca de lo que es lo humano, lo que es universal, lo que podría ser el significado y la sustancia de la política internacional, no son suficientes. Para cumplir con los objetivos de la transformación democrática radical, necesitamos saber que nuestras categorías más fundamentales pueden y deben ser expandidas para tornarse más incluyentes y sensibles a toda la gama de poblaciones culturales. Esto no significa que un ingeniero social determine a distancia cómo incluir mejor a todos en sus categorías. Significa que la categoría misma debe estar sujeta a una revisión desde una multitud de direcciones, y que debe surgir de nuevo como el resultado de la traducción cultural a la que se la somete. (Burgos 2002, p. 316)

En síntesis, Butler (2000) es una escritora comprometida cuya bandera filosófica es la proliferación y problematización de géneros, el cultivo de sexualidades disidentes y disruptivas. Su compromiso ético también conlleva un compromiso político y social por hacer de la filosofía una herramienta de crítica del presente. Por supuesto, la propuesta de Foucault de la multiplicación del poder es la base de sus propuestas teóricas, sin embargo, efectúa un poderoso descentramiento a "la estética de la existencia" que aún sigue pertrechada en un romanticismo pequeñoburgués falocrático. En este sentido, para Butler (2016), el individualismo soberano es una ficción que puede ser engañosa y nociva en la búsqueda de un auténtico quehacer de liberación, porque invisibiliza las formas de control y dominación. En su perspectiva, es claro que se puede romper con ciertas normas si y sólo sí se es capaz de recurrir a la intervención de normas compensatorias, asumiendo que la matriz de relaciones de subjetivación "no es una red integrada y armónica, sino un campo de desarmonía potencial, antagonismo y disputa. También suponen cambios significativos o ruptura, no sabemos con exactitud quiénes somos o qué significa yo cuando lo pronunciamos” (Butler, 2016, p. 18). Las rupturas, los fragmentos, las turbulencias e incertidumbre forman una identidad evanescente y frágil. 
El reconocimiento de que somos efecto de fuerzas previas poderosas no anula la libre acción humana, sino que la condiciona y la coacciona a un margen cada vez más estrecho de maniobra; reconocer este margen, por más limitado que sea, es una tarea del postfeminismo político de nuestro tiempo que asume las consecuencias radicales de la crisis del humanismo antropocéntrico eurocentrista y falocentrista. Frente a las éticas modernas autocentradas en el sujeto, Butler efectúa un pequeño giro hacia una ética descentrada y relacional que asume la interpelación discursiva del otro como fundacional, aunque su fundamento sea frágil, performativo, contextual, finito y, por ende, siempre político.

La extrema fragilidad y provisionalidad del yo ético da cuenta de una parte maleable y creativa, puesto que ese yo nunca deja de estar inacabado; es una obra en proceso, en devenir constante, luego entonces, es un espacio de autocreación finita de sentido. La crisis del humanismo falocéntrico, lejos de precipitarnos en la impotencia, nos posibilita asumir el descentramiento del sujeto moderno como una nueva oportunidad para replantear las identidades subjetivas y su compromiso ético-político con otra forma de experimentar el sí mismo y la relación con el otro. Cierto, estamos lejos de la estética de la existencia romántica estilo Baudelaire-Foucault, pero también estamos lejos del pesimismo o relativismo de las sociedades individualistas posmodernas. El compromiso ético-político del sujeto descentrado es más efectivo, más concreto, más limitado... más tangible y asequible a nuestro tiempo.

La crisis del sujeto moderno queda expuesta en la crisis de sus garantes políticos, como serían las ideas de Estado-Nación y Democracia; ambas ideas naufragan en el océano de la insignificancia creciente. Los gobiernos actuales más difícilmente se pliegan a la soberanía del Estado Moderno, mientras que se impone una lógica trasnacional de un capital financiero global, y la idea de democracia representativa se vacía de todo contenido, al tiempo que emergen otras formas de organización política inédita. Así, grupos, colectivos y multiplicidad de movimientos sociales exceden, no pocas veces con violencia furibunda, las diversas formas de participación social y política normalizadas o establecidas por el establishment. 
Por ende, repensar la política y el sujeto bajo el horizonte de crisis de la modernidad y replanteamiento del posmodernismo conlleva una suerte de doble estrategia de asumir la crisis y debacle de las narrativas modernistas falocéntricas universalistas, y al mismo tiempo, la exigencia de reinventar alternativas ante dicha crisis de las significaciones centrales de la modernidad capitalista falocéntrica. Lo anterior también implica, según Butler, un posicionamiento que sea capaz de sustraerse a los lugares comunes del posmodernismo y postestructuralismo y su consabida cantaleta del "fin del sujeto". La pensadora norteamericana es muy consciente de que si en este lado del Atlántico posmodernos, postestructuralistas y deconstruccionistas son metidos todos en un mismo saco, en la escena continental hay una serie de diferencias sustantivas que a veces cobran formas en cruentas disputas intelectuales, como ejemplos paradigmáticos el antagonismo entre entre Foucault y Derrida, o DeleuzeGuattari y Lacan, por mencionar solamente dos arenas del debate célebres. Para Butler se trata de situarse en una posición paradójica: "no deshacerse de los fundamentos defendiendo una posición conocida como antifundamentalista" (Butler, 2001ª , p. 15). La tarea es interrogar la exigencia de una fundamentación contingente, pero no relativista, y claro está, que no recaiga en un universalismo hueco. Desde la perspectiva de Butler, la crítica del sujeto moderno falocéntrico no es una negación o repudio del sujeto sino más bien una estrategia de interrogación de su construcción y una elucidación anticipatoria de su posible resignificación. La cuestión central no es decir adiós al sujeto sino reformular es noción desde su problematización tanto epistemológica como ético-política. De ninguna manera es casual que respecto al replanteamiento del sujeto político contemporáneo Butler (2001a, p. 31) ejemplifique "las muy duras críticas del sujeto como instrumento de hegemonía imperialista occidental a Gloria Anzaldúa y Gayatri Spivak”. De ahí que la problematización política del sujeto no significa necesariamente su liquidación:

Deconstruir al sujeto no es negar ni desechar el concepto; por el contrario, la deconstrucción implica solamente que suspendamos todo compromiso con aquello a lo que el término, "el sujeto", se refiere, y que consideremos las funciones lingüísticas a las que sirve en la consolidación y el ocultamiento de la autoridad. Deconstruir no es negar o hacer a un lado, sino cuestionar y, tal vez lo más importante, abrir un término, 
como el sujeto, a una reutilización o recolocación que previamente no ha sido autorizada (Butler, 2001ª , p. 32).

Por tanto, para Butler reconstruir el sujeto político femenino feminista no es renunciar al sujeto sino replantarlo desde otro horizonte muy distinto al habitual. Pues conlleva también problematizar los términos "mujeres" y "nosotras", pues en ambos se trata de categorías eurocéntricas, clasistas y excluyentes que dejan de lado a las mujeres negras, indígenas y otras personas que no gozan de los derechos políticos de mujeres ciudadanas blancas del primer mundo. De manera particular Butler destaca tanto del posmodernismo como de la deconstrucción su exigencia de interrogar la construcción del sujeto y la exigencia genealógica de su impugnación, pero al mismo tiempo, nos remite a la exigencia nietzscheana de su transvaloración. Su crítica es afirmativa porque no está en contra el sujeto moderno sino a favor de su resurrección en una nueva subjetividad descentrada.

\section{Un origen evidente, aunque oculto: el pensamiento nietzscheano}

Nietzsche ha sentado los presupuestos para la teoría del poder de Foucault y, por ende, para la crítica de la sexualidad binaria realizada por Butler, en los términos antes señalados. Ya Habermas (1994), quien no es precisamente un adepto nietzscheano, había afirmado que Nietzsche y Heidegger constituían la plataforma giratoria de la posmodernidad; dicho sea de paso, también contraataca con un ensayo intitulado La crítica nihilista del conocimiento en Nietzsche, intentando, sin lograrlo, de forma desesperada, salvar(se) del naufragio del perspectivismo relativista que mina y contamina todo presupuesto de comunicación $\mathrm{y}$ comunidad trascendentales. Como sabemos, Nietzsche es un pensador de las arenas movedizas, destructor de todas las permanencias, de todas las regularidades, verbigracia, el yo, el trasmundo metafísico, el objeto externo a la conciencia, etc. Pensador de lo inestable, Nietzsche ha minado la idea conforme a la cual existe algo en sí, porque lo "en sí”, es decir, lo que no cambia, no deviene, no es otra cosa que un mero prejuicio de los filósofos. En realidad, según su perspectiva, todo lo que existe es un ensamblaje de muchas partes rotas, fragmentadas; no hay unidad. Hay pluralidades que forman unidades. En suma, como ya se 
ha dicho, no hay nada metafísico, nada fuera del tiempo y del devenir; todo es performativo. Todo depende del poder... de la voluntad de poder y las fuerzas inmanentes que nos atraviesan. Son los poderosos los que establecen lo que es bueno, malo, anormal, verdadero o falso.

La genealogía de la moral nietzscheana inicia la genealogía del Hombre y de la modernidad en su conjunto, la deconstrucción derridiana, de la cual abreva el sentido crítico de Butler, se asume como heredera tanto de Nietzsche, Derrida y el pensamiento postnietzscheano contemporáneo. El sentido profundo de la poderosa intuición de "transvaloración de todos los valores" conlleva el advenimiento de otro humano más allá del humanismo y más acá de la transparencia del sujeto universal. Ese otro humano respecto al significante hegemónico despótico del Hombre Universal no sería otro sino el advenimiento del superhombre o ultrahombre como génesis de otra humanidad que atienda y entienda el sentido de la inmanencia de la tierra y su celebración dionisiaca soberana. Una humanidad otra más sabia, más rica en contradicciones, heterogeneidades y multiplicidades de todo tipo. El sueño nietzscheano se atisba en la resemantización de subjetividades nómades de importantes pensadores feministas como Judith Butler, Gloria Anzaldúa, Rossi Braidotti, entre otras.

Es en este contexto donde ha sido posible la proliferación de nuevas subjetividades en resistencia, toda vez que no hay nada definido, por tanto, es la hora del subalterno marginado y anómalo, del sujeto excluido de la historia y del discurso. Y más: una nueva aurora aparece en el horizonte, luego del cumplimiento de la muerte de Dios como fin de toda certidumbre, una vez que el Hombre, como su emisario y comisario plenipotenciario, yace en ruinas. La debacle del humanismo antropocéntrico es una crisis que anuncia nuevas transformaciones. Si cambia el dispositivo de poder, cambia la perspectiva, cambia la realidad. Quizá, bajo estos presupuestos, podamos acceder a un mundo más incluyente y justo. Lo cierto es que el mundo contemporáneo presenta efectos paradójicos, se contrae y se expande sin cesar; todas las lecturas y relecturas están sujetas a reajustes constantes. En todo caso, el fin del humanismo antropocéntrico no es tan malo o negativo, más bien es una valiosa oportunidad para el 
advenimiento de otra humanidad que acoja las diferencias de todo tipo, en el contexto de una pluralidad necesaria y deseable donde tengan cabida las alteridades que nos constituyen.

El tema y problema apremiante de la agenda política e intelectual de nuestro tiempo es, justamente, la reconfiguración de un juego afirmativo de subjetivaciones en los umbrales del pensamiento hegemónico y en los intersticios de la sociedad de control dominante. Habría una tradición filosófica que va de los hedonistas y cínicos antiguos hasta Spinoza, Nietzsche y Bergson que abreva, en su búsqueda de un fundamento, en lugar de una esencia metafísica única e indisoluble, en una fundamentación pluralista, materialista y múltiple, que recoge la pluralidad de fuerzas afectos, potencias y deseos en y desde la inmanencia, la vida sin más, y que asumiendo la finitud y la contingencia más radicales no renuncia a repensar la invención de normas y valores. En esta encomienda fundamental de nuestro tiempo resulta imprescindible abrirse de manera real y efectiva a las alteridades muy otras de Occidente, la crítica genealógica y deconstructiva resulta parcial e insuficiente si no considera en serio las apuestas y propuestas de otras cosmovisiones que se sustraen al imaginario occidental y la modernidad capitalista. En este sentido el pensamiento latinoamericano que abreva en la fontana de cosmovisiones indígenas y de espacios socioculturales de resistencia militante contribuyen a la renovación auténtica de la agenda intelectual y social de nuestra contemporaneidad. En este sentido resulta imprescindible la recuperación de tradiciones intelectuales y culturales que se expresan en el arte y la literatura de Nuestra-América, para utilizar la afortunada expresión de José Martí. El Ethos Barroco y Neobarroco latinoamericano se asume, mucho más que como un estilo o tendencia artística, como un espacio plural de problematización del pensamiento y la cultura en general. Habría una serie de intelectuales y artistas latinoamericanos que han buscado repensar en los márgenes del pensamiento y la cultura hegemónicos alternativas reales ante la devastación inminente de sentido. La lista es muy amplia, baste nombrar, a manera de ejemplos paradigmáticos a Sor Juana Inés de la Cruz, Rosario Castellanos, José Lezama Lima, Haroldo de Campo, Ángel Rama, Bolívar Echeverría, entre otros. Aquí trazamos una deriva provisoria, parcial, insuficiente, más no arbitraria, a partir de algunas intuiciones de la notable pensadora y escritora Gloria Anzaldúa. La intención expresa es la de trazar apenas un esbozo en torno a 
una posible relectura de la crisis del sujeto universal de la modernidad falocéntrica en y desde su replanteamiento en los umbrales y márgenes del pensamiento latinoamericano que atisba el advenimiento de otras subjetivaciones inéditas.

\section{Anzaldúa y el mestizaje de subjetividades subalternas}

La debacle del humanismo antropocéntrico tiene los más diversos efectos y afectos. La emergencia de subjetivaciones inéditas rehace la relación del sujeto consigo y con el mundo y permite asir la crisis como oportunidad de transformación. Lejos de la plañidera posmodernista reaccionaria habrá que tener miras hacia otro porvenir para rehacer una agenda teórica y política, tan urgente como necesaria desde nuestros contextos periféricos. Habrá que repensar la producción de subjetividad desde la interpelación de la alteridad en una geopolítica de producción de conocimiento siempre situada y anclada a un vector de desterritorrialización y frente a reterritorializaciones hegemónicas. La producción de subjetividad en tanto autocreación de libertad efectiva se juega en contextos de interacción dinámica que exige repensar el saber y su relación con prácticas emancipatorias. Y es en este sentido que cobra particular relevancia la recuperación de los sujetos subalternos en y desde contextos periféricos como América Latina, siendo la idea de subalternidad un hilo conductor para salir del laberinto contemporáneo.

En sus cuadernos de la cárcel, en 1930, justo antes de redactar las notas sobre y la noción de hegemonía, Antonio Gramsci elucida uno de sus núcleos centrales de su pensamiento en torno a la categoría analítica marxista de subalternidad. El concepto de lo subalterno destaca la dimensión subjetiva de la subordinación bajo el dominio de una hegemonía, y muestra su réplica de resistencia continua. La hegemonía del poder no se puede comprender sin la oposición del antagonismo y resistencia que le imprimen los procesos de subjetivación marginal, la cual conlleva también un proceso interminable e intermitente de autonomización y lucha frente a todas las formas impuestas de dominación. 
El concepto de subalterno elaborado por Antonio Gramsci en el marco de sus reflexiones teórico-políticas generó una perspectiva que permitió abrir el marco de análisis de los procesos de subjetivación política... Partiendo de las reflexiones de Gramsci podemos entender la subalternidad como condición y como proceso de desarrollo subjetivo - de subjetivación política centrada en la experiencia de la subordinación- que incluye combinaciones de aceptación relativa y de resistencia, de espontaneidad y conciencia. esto implica distinguir tanto niveles y dimensiones como situaciones y momentos, reconocer distintas formas y pasajes, diversas manifestaciones de la subalternidad, que sería necesario adjetivar. Al mismo tiempo, ampliar la mirada hacia procesos y dinámicas de subjetivación política que rebasan la resistencia -como postura defensiva-supone incorporar otras dimensiones y otros conceptos (Modonesi, 2010, p. 52).

En este sentido el feminismo chicano subalterno de Gloria Anzaldúa (2006) potencia el devenir minoritario del subalterno como sujeto rebelde de resistencia a partir de una escritura que rompe fronteras entre poesía, ensayo, ficción y crítica social, pero también exige el replanteamiento de la praxis creadora de subjetivaciones disidentes. Como bien ha señalado la crítica de la cultura y notable ensayista Nelly Richard las teorías feministas angloeurocéntricas que se reproducen en la academia universitaria mundial tienden a borrar la realidad específica y la experiencia singular-colectiva de las mujeres que están en los márgenes de la metrópoli cultural-intelectual-económica:

La academia norteamericana desempeña hoy, una "función-centro" que traduce la producción local del feminismo latinoamericano, subordinándola a su registro hegemónico. Existen buenas razones para para defender una otredad local en relación con esta hegemonía académico-institucional de la teoría feminista metropolitana que borra singularidades y diferencias (de tiempos y lugares) con la síntesis homogeneizante de sus abstracciones globales... En contra de este mercado literario globalizado, la crítica feminista debería preocuparse de un femenino que no se arme como representación homogénea, sino como vector de descentramiento significante que interrogue los mecanismos de centralización de sentido. Para ello hace falta un feminismo no de la diferencia sino de las diferencias: un 
feminismo que postule múltiples combinaciones de signos y "transiciones contingentes" (Richard, 2007, pp. 491-496).

En este sentido la deconstrucción del género y de las teorías euro-logo-falocéntricas es un ejercicio ético-político que implica ir más allá de las configuraciones discursivas y repensar los procesos y prácticas constituyentes del juego de subjetivaciones, y para ello, es crucial aventurarse en la reinvención plural de feminismos como espacios de impugnación de cualquier teorización o matriz teórica que convalide y valide formas de dominación, colonialismo e imperialismo de cualquier índole. De ahí la relevancia de alguien como Anzaldúa. Pensadora activista que se ubica en los márgenes del Imperio llevando de contrabando las visiones-versiones del universo cultural subalterno gestado en los márgenes del mestizaje latinoamericano, siendo dicho mestizaje un espacio de intersección y problematización existencial y política. La rebelde feminista -encarnada y teorizada por ellalleva en su interior: La Bestia de Sombra, esa parte insurrecta que no obedece ningún mandato: "La conciencia de la Nueva Mestiza, aunque rechaza nociones estáticas del ser, valora profundamente la individualidad de la chicana" (Anzaldúa, 2006, p. 17). La Nueva Mestiza integra ambigüedad, contradicción, violencia cotidiana y resistencia en estado puro.

El mestizaje subalterno es aquí fruto de violencia extrema y barbarie que sufre el sujeto colonizado, estamos lejos de cualquier perspectiva posmodernista idílica. Sin embargo, también posibilita una contra-violencia que tiene fuerza e inventiva de trastocar el orden establecido. La apelación a la identidad chicana es apelación táctica, siempre politizada, una forma de resistencia cultural identitaria marginal. Lejos de toda perspectiva esencialista, se invoca el mestizaje subalterno, descentrado, como estandarte contra el sistema capitalista patriarcal e imperialista. La apelación a la cultura mestiza como una comunidad política imaginada es reclamo territorial de una estrategia de subjetivación e intersubjetividad en una cartografía nómada, simbólica y materialista.

De ahí la importancia de una relectura de la Coatlicue-Virgen de Guadalupe-Malinche en clave feminista crítica subalterna decolonial. Como los labios femeninos, la Nueva Mestiza 
traza un devenir minoritario en los bordes del español e inglés. Abre un devenir monstruoso en el Spaninglish, lengua chicana como espacio de mestizaje, "Nepantlismo mental" como tierra de nadie, interzona, entre que posibilita la relación dinámica entre una subjetividad nomádica descentrada y una territorialidad fronteriza en conflicto. Conciencia diferencial del margen como una deconstrucción salvaje.

El sujeto expresado y encarnado en la Nueva Mestiza sintetiza luchas traicionadas y potencias de ruptura sin parangón. Agente de reinterpretación como plasticidad histórica situada, la lucha de la Nueva Mestiza conlleva un llamado a los desclasados y excluidos, cuya capacidad de hacer cortocircuito la dominación "con su existencia callada pero indomeñable" (Anzaldúa, 2006, p. 42). La deconstrucción y desterritorialización que lleva a cabo el sujeto nómade descentrado de la Nueva Mestiza es un ejercicio de autocrítica de toda identidad esencialista fija, pero no renuncia a la apertura de una epistemología no occidental que visibilice la emergencia de saberes menores y marginales. La cuestión del saber y de la teorización de nuevas subjetividades se interroga desde su sentido ético-político.

El feminismo marginal subalterno de Anzaldúa radicaliza el antagonismo, la autonomía y la subalternidad propuestos por Gramsci, y permite entender y atender otros procesos y prácticas de subjetivación más allá del replanteamiento de Foucault y Butler de la crisis del humanismo antropocéntrico, pues solamente abriéndose auténticamente un pensar y sentir otro podríamos estar en condiciones de repensar de forma radical la quiebra del humanismo antropocéntrico y falocéntrico. La lección de Anzaldúa es que un feminismo radical no puede prescindir de las experiencias otras de miles de mujeres marginadas y excluidas de los paradigmas de pensamiento y de vida eurocéntricos. Quizá la emergencia de la subalternidad sea una de las notas distintivas de nuestro tiempo. La propia Butler había ya reconocido que los significantes Mujeres y Nosotras, expresan una identidad que se suele identificar, en términos prácticos, con las mujeres blancas, clase media alta o élite dominante, dejando de lado fuera a las demás mujeres excluidas y marginadas de las demás sociedades. 
El lugar de enunciación posibilita cierta cartografía teórica como mapa rizomático de creación de sentido. De ahí que el replanteamiento del feminismo desde su deconstrucción y problematización en y desde los márgenes de América Latina tendría que servir como catalizador de un pluralismo discursivo vigoroso, a la par, que fundamente el reconocimiento auténtico de la diversidad que nos constituye. En este sentido el importante legado pionero al respecto de Anzaldúa nos conmina a un replanteamiento urgente, y aún vigente, de los estudios de género y la filosofía política en y desde la redescripción de las identidades genéricas:

Como feminista, Anzaldúa se rebela ante el machismo del nacionalismo chicano y ante sus definiciones limitadas y "disciplinarias" de la tradición; a la vez como chicana confronta el etnocentrismo y el clasismo del movimiento feminista anglosajón; y como lesbiana cuestiona tanto la homofobia del nacionalismo chicano como las visiones heterosexistas del género del movimiento feminista. A partir de su propia experiencia, nos muestra las limitaciones de aquellas políticas de la identidad que parten de un criterio de autenticidad y exclusión (2007, Hernández, p. 507).

\section{En lugar de conclusiones: continuar el diálogo}

Si todo es provisorio, también este juicio provisional lo es. Sin certezas, nos quedan interrogantes y campos de problematización. Sin brújula preestablecida, tampoco sabemos ya cuáles son las preguntas correctas, buenas o verdaderas. Quizá nuestro destino sea habitar la errancia sin fin: el destino del desatino sin término posible. Más todavía: en un poema memorable, el poeta Octavio Paz (2014) escribe: "La palabra del hombre es hija de la muerte. / Hablamos porque somos mortales: / las palabras no son signos, son años. / Al decir lo que dicen los nombres que decimos / dicen tiempo: nos dicen. / Somos nombres del tiempo (Paz, 2014, p. 338, cita ligeramente modificada). Y la conclusión es que: conversar es humano, demasiado humano. Aún nos queda la conversación finita-infinita, la memoria de una condición humana en ruinas. Habitantes de las ruinas, disponemos de la frágil herencia de 
huellas, fragmentos, retazos, cicatrices y añoranzas, pero también del juego infinito de reapertura sin fin como potencia en estado puro.

La pluralidad ontológica es necesaria para rehacer el rostro del mundo en las ruinas del Hombre, para que emerjan miles de rostros y rastros. Por doquier, la alteridad de subjetivaciones subalternas marginales ha multiplicado sus fases y antifaces. No hay remedio y ¡qué bueno que así sea! Ya no se puede rehacer una cartografía del mundo y del ser humano que no sea de manera aproximada, contextual, dialógica, fragmentaria y fractal. Ahora bien, lejos de la queja plañidera, vista la situación desde los márgenes e intersticios en y desde una modernidad periférica e insular, la actual crisis se presenta como un umbral de múltiples posibilidades de transformación de los significantes hegemónicos de una cultura y un pensamiento logo-falo-eurocéntricos. La apertura ontológica y política instaura un horizonte complejo por-venir, plantea y replantea un horizonte abierto de posibilidades y potencias múltiples.

La apertura del horizonte por venir está sustentada en la posibilidad de atisbar procesos otros de subjetivaciones inéditas, donde la alteridad real, de carne y hueso, que había sido por completo invisibilizada y anulada de toda representación y figuración hoy comienza a adquirir un nuevo rostro en el embate cruento de antagonismos y hegemonías. Ir del posfeminismo y la posmodernidad al encuentro con las alteridades auténticas subalternas es un paso que podría anticipar el advenimiento de un humanismo descentrado de subjetivaciones muy otras y diversas. Este ese el trayecto que se ha intentado bosquejar de Nietzsche a Foucault y de éste a Butler y de Judith a Gloria Anzaldúa como un gesto performativo y rizomático de repensar una nueva pluralidad tan inédita como necesaria. El pluralismo teórico de los feminismos diversos y divergentes en y desde los márgenes de la Metrópoli potencia un feminismo decolonial como espacio heterogéneo disidente tan necesario como pertinente en el diálogo contemporáneo en torno a la generación de alternativas ante el colapso de la modernidad capitalista. 
El hechizo de la mismidad identitaria se ha roto para siempre; la caja de Pandora de la diferencia no termina de figurar y configurar en el caleidoscopio de un tiempo histórico difuso un libre juego de subjetivaciones anómalas, anormales, disidentes. El pluralismo ontológico y político ha herido de muerte el antropocentrismo hierático; todo ser se declina como existencia política múltiple. Existir ahora es persistir e insistir en el ser. La existencia se afirma enérgicamente en el grado cero de una sobrevivencia limítrofe. Quizá Jacques Derrida tenía razón en afirmar la sobrevivencia como forma privilegiada de la condición humana contemporánea, aunque se equivocaba en su énfasis nietzscheano de vitalidad soberana (Derrida, 2006). Sin pena ni gloria, sobrevivir es hoy un asunto que casi nos cuesta la vida, empero, la experiencia creadora de miles de subjetividades y colectivos están fraguando el sueño de formas otras de ser humano en el umbral. La crisis conlleva un reto y un desafío de repensar la emergencia de posibilidades inéditas bajo la ausencia de los significantes hegemónicos y la apertura de nuevas formas de pensamiento y de producción de subjetividades otras.

La debacle del Sujeto Universal, sujeto logo-falo-eurocéntrico, conlleva una serie de retos y desafíos apremiantes, estamos ante la inédita posibilidad de que emerjan nuevas formas de subjetivación, es un acontecimiento histórico-político fundamental y fundacional, la crisis de los paradigmas hegemónicos posibilita la gestación, lenta y pacientemente, de nuevas subjetivaciones singulares, disruptivas, marginales e intempestivas. En este sentido el caldo de cultivo que potencia el juego de mestizajes subalternos da pie a subjetivaciones otras más allá de la modernidad capitalista y más acá de las mediaciones e intermediaciones de una experiencia corpórea de subjetividades e intersubjetividades descentradas, anómalas, disidentes. En tal contexto, obras absolutamente singulares como las de Gloria Anzaldúa resignifican por completo la creación de alternativas en un panorama de crisis generalizada y desafíos ingentes, subjetivaciones en y desde las nuevas mestizas y mestizajes están generando márgenes activos en miasmas de la maquinaria imperial; los márgenes y umbrales hoy generan espacios de participación política novedosa y subversiva. 


\section{Referencias}

Adorno, T. (2005). Dialéctica negativa. La jerga de la autenticidad. Obra completa 6, Madrid. Akal.

Anzaldúa, G. (2006). Borderlands. La frontera. La Nueva Mestiza. Madrid. Capitán Swing.

Baudrillard, J. (1996). El crimen perfecto. Anagrama. Barcelona.

Burgos Díaz, E. (2002). Ensayos de filosofía de la cultura. Biblioteca Nueva. Zaragoza.

Butler, J. (1990). Teoría feminista y teoría crítica. Valencia. Ediciones Alfons el Magnanim.

Butler, J. (2000). Historia, género e identidades sexuales. Buenos Aires. Edelp.

Butler, J. (2001). El género en disputa. Barcelona. Paidós.

Butler, J. (2001a). Fundamentos contingentes: el feminismo y la cuestión del posmodernismo. Revista de estudios de género. La Ventana, No. 13, 2001. Consultado el 18 de octubre del 2021 en http://revistalaventana.cucsh.udg.mx/index.php/LV/article/view/549

Butler, J. (2005). Cuerpos que importan. Sobre los límites materiales y discursivos del sexo. Buenos Aires. Paidós.

Butler, J. (2006). Deshacer el género. Paidós. Barcelona.

Butler, J. (2008). “¿Qué es la crítica? Un ensayo sobre la virtud de Foucault”. VV. AA. Producción cultural y prácticas instituyentes. Líneas de ruptura en la crítica institucional, Madrid: Traficantes de Sueños. 
Butler, J. (2010). Cuerpos aliados y lucha política. Hacia una teoría performativa de la asamblea. Paidós. Barcelona.

Butler, J. (2016). Los sentidos del sujeto. Madrid. Herder.

Deleuze, G. (2006). Post-scriptum sobre las sociedades de control. Polis [En línea], 13 | 2006, Publicado el 14 agosto 2012; consultado el 26 octubre 2020. URL: http://journals.openedition.org/polis/5509

Derrida, J. (2006). Aprender por fin a vivir. Entrevista con Jean Birnbaum. Buenos Aires. Amorrortu.

Foucault, M. (1985). Herculine Barbin llamada Alexina B. Madrid. Revolución.

Foucault, M. (1999). Historia de la sexualidad, 1- La voluntad de saber. México. Siglo XXI.

Habermas, J. (1994). Sobre Nietzsche y otros ensayos. Madrid. Tecnos.

Hernández, A. (2007). De feminismos y postcolonialismos: reflexiones desde el sur del Río Bravo, en Colonialidad y crítica en América Latina. Puebla: Universidad de las Américas.

Izuszquiza, I. (2002). Caleidoscopios. La filosofía occidental en la segunda mitad del siglo XX. Madrid. Alianza.

Klossowski, P. (2008). Un tan funesto deseo. Buenos Aires. Las Cuarenta.

Lyotard, J-F. (1990). La condición postmoderna. México. Rei.

Modonesi, M. (2010). Subalternidad, antagonismo, autonomía. Marxismos y subjetivación política. Buenos Aires. UBA Sociales Publicaciones-CLACSO. 
Paz, O. (2014). Lo mejor de Octavio Paz. El fuego de cada día. Obra poética. México. Conaculta-Seix Barral.

Richard, N. (2007). “Experiencia y representación: lo femenino, lo latinoamericano”, en Colonialidad y crítica en América Latina. Puebla: Universidad de las Américas.

Zourabichvili, F. (2004). Le vocabulaire de Deleuze. Paris. Ellipses. 
REVISTA INTERNACIONAL DE FILOSOFÍA TEÓRICA Y PRÁCTICA

Volumen 2. Número 1. Enero - Junio 2022 ISSN: 2745-0333 (En línea) 